\title{
As armas em Maquiavel
}

\author{
The arms in Machiavelli
}

\section{Patrícia Fontoura Aranovich}

Resumo: As considerações que se seguem partem de algumas dúvidas que surgem na leitura da obra de Maquiavel no que diz respeito ao confronto entre, de um lado, o evidente interesse de Maquiavel pela questão das armas - interesse este teórico e prático, que nem sempre é devidamente considerado - e, de outro lado, a ausência deste assunto em um lugar chave de sua obra, a saber, no início da História de Florença.

Palavras-chave: Maquiavel, Florença, Roma, Exército, República

\begin{abstract}
The following considerations start from some questions arisen out of the reading of Maquiavel's works regarding the comparison between, on the one hand, his profound interest in the issue of arms - a theoretical and practical interest which is not always carefully considered -, and, on the other hand, the absence of this matter in a key point of his work, namely the beginning of "The History of Florence".
\end{abstract}

Keywords: Machiavelli, Republic, Arms, Rome, Florence

Podemos constatar a centralidade do tema das armas em sua obra desde o Príncipe, em que diversas passagens, além dos capítulos I2, I3 e I4, referem-se à questão das armas. É também o objeto principal de um dos três livros dos Discorsi e a ele foi dedicado um livro, $A$ arte da guerra. Além disso, seu interesse prático pela questão é comprovado pelo fato de Maquiavel ter tentado ordenar um exército florentino (I505).

No Príncipe, é apresentada a ideia de que as boas armas, isto é, as armas próprias, constituem, junto com as leis, os fundamentos tanto dos principados como das repúblicas:

\footnotetext{
"Prof ${ }^{\mathrm{a}}$. Adjunta da Universidade Federal de São Paulo (UNIFESP).
} 
Dissemos acima como é necessário a um príncipe ter bons fundamentos; caso contrário, necessariamente se arruinará. Os principais fundamentos de todos os estados, tanto dos novos como dos velhos ou dos mistos, são as boas leis e as boas armas. Como não se podem ter boas leis onde não há boas armas, e onde há boas armas costumam ser boas as leis, deixarei de refletir sobre as leis e falarei das armas'.

O tema das armas próprias aparece nos Discursos sobre a primeira década de Tito Lívio em termos semelhantes, como no intitulado "Da censura merecida pelo príncipe e pela república que não têm armas próprias", em que vemos que cabe ao novo príncipe (o estado) fundar suas bases, e isso em um tempo relativamente curto:

Os príncipes atuais e as repúblicas modernas que não têm soldados próprios para a defesa e o ataque devem envergonhar-se e, diante do exemplo de Tulo (Ostílio), concluir que tal deficiência não se dá por falta de homens aptos para a milícia, mas por culpa deles mesmos, que não souberam fazer de seus homens soldados. Porque Tulo, ao suceder no reino, não encontrou nenhum homem que alguma vez houvesse ido à guerra, visto que Roma estivera em paz durante quarenta anos: apesar disso, como tencionasse entrar em guerra, nunca pensou em valer-se dos samnitas nem dos toscanos, nem de outros homens acostumados às armas, mas, como homem prudentíssimo que era, deliberou valer-se dos seus. $\mathrm{E}$ foi tão grande a sua virtù, que, durante o seu governo, em pouquíssimo tempo conseguiu fazer deles soldados excelentes. E a mais verdadeira das verdades é que, se não houver soldados onde há homens, isso provém de uma falha do príncipe, e não de outra falha qualquer, do lugar ou da natureza ${ }^{2}$.

A partir apenas destes dois exemplos, mas que são significativos do modo como a questão é apresentada e que comprovam sua centralidade na obra, nos voltamos para verificar como esta questão aparece na História de Florença, obra na qual, como se disse, o tema das armas é apresentado como secundário com relação às discórdias civis:

\footnotetext{
${ }^{\mathrm{I}}$ MAQUIAVEL, O Príncipe, XII.

${ }^{2}$ MAQUIAVEL, Discorsi, I, 2I.
} 
Quando deliberei escrever as coisas feitas pelo povo florentino, dentro e fora de Florença, minha intenção era começar a narração pelo ano I434 da era cristã, quando a família dos Medici, graças aos méritos de Cosimo e de Giovanni, seu pai, ganhou mais autoridade que qualquer outra em Florença; isso porque me parecia que messer Lionardo d'Arezzo e messer Poggio, dois excelentes historiadores, já haviam narrado, com particularidades, todas as coisas sucedidas até aquele ano. Mas, depois de ler diligentemente seus escritos, para ver com que ordem e de que modo procediam, a fim de que, imitando-os, nossa história recebesse melhor aprovação dos leitores, percebi que foram muitíssimo diligentes na descrição das guerras travadas pelos florentinos contra os príncipes e os povos estrangeiros, mas que, no que se refere às discórdias civis e às inimizades internas, bem como aos seus efeitos, eles calaram de todo uma parte e descreveram a outra com tanta brevidade que nela os leitores não podem encontrar utilidade nem prazer algum ${ }^{3}$.

Mais à frente, ele conclui:

Então, depois de considerar tais coisas, mudei de propósito e decidi começar minha história pelo princípio de nossa cidade. E, como não é minha intenção ocupar o lugar alheio, descreverei com particularidades, até I434, somente aquilo que ocorreu dentro da cidade, e sobre as coisas de fora só direi o que for necessário ao entendimento das de dentro; depois, passado o ano de I434, escreverei com particularidades ambas as partes ${ }^{4}$.

Portanto, os quatro primeiros livros serão voltados às coisas internas e os outros quatro seguirão o que ele supõe que seja o modelo de narrativa histórico correto, que narra os assuntos interno, mas enfatiza os externos ${ }^{5}$. E, para suprir a ausência de assuntos externos até essa data, o primeiro livro narra em 39 capítulos a história da Itália desde o declínio de Roma até I434.

\footnotetext{
${ }^{3}$ MAQUIAVEL, História de Florença, Proêmio.

${ }^{4}$ MAQUIAVEL, História de Florença, Proêmio.

"Do ponto de vista do conteúdo, os eventos político-militares são o tema histórico por excelência, o que inclui a narração das batalhas, mas também os discursos dos comandantes a seus homens, as alianças e a ilustração dos costumes. Estes eventos são examinados, portanto, em todas as suas possíveis articulações: causas, conseqüências, deslocamentos geográficos, acontecimentos etc. A exposição da origem das cidades sua estrutura jurídica e política, as tradições e propensões dos habitantes — conferia dignidade e variedade à narrativa. Entretanto, a maior parte de seu interesse está voltado à política externa de um Estado" (Gilbert, F. I965, p. 209).
} 
Esta organização dos livros, inicialmente, não levanta suspeitas, pois, de fato, a análise que Maquiavel faz das questões internas das repúblicas e a ruptura com a concepção da concórdia na política são tidas, com justiça, como as mais relevantes de sua obra. Desse modo, deixar de lado a guerra, tema historiográfico consensual em sua época, para concentrar os esforços narrativos na composição interna de forças e autoridades na república parece coerente com essa perspectiva.

Entretanto, é na argumentação do porquê poder deixar isso de lado na primeira metade da narrativa que surge um primeiro problema, ainda não tão claro ou grave. Tratase de entender, como conciliar a deferência para com os "dois excelentes historiadores" - a recusa de ocupar o lugar alheio - com a afirmação de que não cumpriram devidamente com seus deveres de historiadores. Além disso, observa-se que, a despeito da disposição de dizer o mínimo sobre as coisas externas, há várias narrativas de guerra e questões relativas às armas, embora de modo algum na mesma proporção que na segunda parte. É plausível que uma razão da diferença entre a primeira e a segunda parte da história seja o fato de que,a partir de I434, é preciso que Maquiavel se afaste das questões internas para não se contrapor em sua narrativa aos Medici, senhores a partir de então da cidade e os que encomendaram e pagaram pela composição da história. Isso por si só já explicaria a necessidade de dedicar-se quase inteiramente às questões externas.

Esta resposta, apesar de poder ser considerada suficiente, dada a situação pessoal de Maquiavel e da política florentina, não deixa de confrontar dois aspectos fundamentais de seu pensamento, visto que o desenvolvimento dos feitos e das ordenações militares é indissociável tanto do modelo historiográfico que segue, quanto de sua concepção de política, em que está estabelecido o vinculo fundamental entre as questões civis e as militares ("os principais fundamentos de todos os estados, tanto dos novos como dos velhos ou dos mistos, são as boas leis e as boas armas"). Assim sendo, a questão a ser investigada é se é possível, e em que termos, narrar especificamente do início da cidade sem as coisas de fora, isto é, sem abordar a questão militar.

Um dos principais modelos historiográficos do Renascimento, e mais ainda para Maquiavel, é a História de Roma de Tito Lívio. Em Tito Lívio, a narrativa da história de Roma, desde a lendária fundação por Rômulo (e por Numa), é a alternância e o entremear das questões internas e externas, isto é, da política e da guerra. Desde o início, o texto passa constantemente das disputas internas entre a plebe e o Senado para as guerras com os vizinhos e discute como cada um desses dois lados age sobre o outro. 
Segundo a narrativa de Tito Lívio, não se pode dizer que Roma tenha um exército: Roma é e nasce como um exército ou, mais propriamente, um grupo armado que se torna civil organizando-se em uma cidade, fundada inicialmente por Rômulo e depois por Numa. O texto oscila entre o elogio e a censura do militarismo romano, e o percurso da narrativa mostra a expansão de Roma e de seu militarismo. A partir desse relato, podemos nos perguntar o que era Roma em sua fundação e como o tema das armas aparece.

Logo no início vemos que Roma não é um grupo de pessoas ou de indivíduos que se unem em busca de proteção, pois, já no quarto capítulo, fica clara a natureza de Rômulo e de seus companheiros:

\begin{abstract}
Assim nasceram os gêmeos e foram criados. Mas, ao chegarem à adolescência, não se contentaram em permanecer no estábulo ou junto ao gado. Embrenharam-se nos bosques e dedicaram-se à caça. Fortalecendo com esse exercício o corpo e o ânimo, em breve já não se contentavam com a caça às feras, mas passaram a investir contra os ladrões carregados de despojos edividiam o saque com os pastores, com os quais se associavam nos trabalhos e nos jogos, à frente de um bando cada vez mais numeroso de jovens ${ }^{6}$.
\end{abstract}

O chefe fundador de Roma e seus seguidores formam, portanto, um grupo ofensivo e não defensivo.

Em seguida, é estabelecido que o fundamento da urbe de Roma é sua fortificação e uma multidão que se reúne, atraída pela novidade, e que sua grandeza está e estará assentada em seu número:

Entrementes a urbe crescia e seu entorno aumentava cada dia, fortificavase mais pela expectativa de multidões futuras do que tendo em vista a população existente. Em seguida, para não ser em vão a grandeza da urbe e para acrescer a ela uma multidão numerosa, Rômulo adotou o modo dos fundadores de cidades que reuniam em torno de si uma multidão de gente de origem humilde e obscura e afirmavam que haviam nascido da terra para eles. E na descida entre dois bosques sagrados, no local em que hoje há uma cerca, criou um asilo onde veio refugiar-se toda a turba dos povos

${ }^{6}$ TITO LÍVIO, História de Roma, I,4. 
vizinhos, mistura indistintas de homens livre e escravos, todos ávidos de coisas novas. Este foi a primeira força da grandeza de Roma?

No capítulo seguinte, Tito Lívio explicita a fraqueza daquela multidão: "Daí por diante, Roma estava bastante forte para não temer nenhuma das cidades vizinhas; mas a falta de mulheres limitava a uma única geração o tempo de sua grandeza. Não havia esperança de prole em casa, nem casamentos com os vizinhos" ${ }^{8}$. Em consequência, seguese o rapto das Sabinas, ação ofensiva que assegura a continuidade de Roma.

Assim, Roma é, em sua origem, o assentamento de um exército ou um grupo armado. É e será uma república permanentemente armada e belicosa, mesmo com as ações pacificadoras de Numa, o que é demonstrado por Tito Lívio em uma das censuras ao militarismo romano, pela exposição da história da construção do templo a Jano, realizada por Numa, cujas portas quase nunca estiveram fechadas.

Narra Tito Lívio:

Tornando-se rei de uma jovem urbe, fundada pela força das armas, Numa preparou-se para fundá-la novamente com base no direito, na lei e nos bons costumes. Ao ver que tais reformas eram inexequíveis em meio a contínuas guerras, pois a vida militar tornava os homens belicosos, e julgando que só poderia abrandar aquele povo feroz desabituando-o do uso das armas, mandou construir um templo a Jano no sopé do Argileto, como símbolo da paz e da guerra: aberto, indicaria que a república estava em guerra e fechado, que estava em paz com todos os povos. Duas vezes apenas ele esteve fechado depois do reinado de Numa: uma vez no consulado de Tito Mânlio, no fim da primeira guerra púnica, e uma segunda vez com o imperadorCesar Augusto, após a batalha de Ácio, quando os deuses permitiram que nossa geração pudesse ver restabelecida a paz na terra e no mar'.

Com as ações pacificadoras de Numa, Roma teria mudado sua natureza:

os povos vizinhos que até então consideravam Roma não como uma urbe, mas como um campo de batalha situado entre eles para perturbar a paz de

\footnotetext{
${ }^{7}$ TITO LÍVIO, História de Roma, I,8.

${ }^{8}$ TITO LÍVIO, História de Roma, I,9.

${ }^{9}$ TITO LÍVIO, História de Roma, I,I9.
} 
todos, viram-se obrigados a venerá-la a ponto de considerarem um sacrilégio atacar uma ciuitas inteiramente voltada para o culto dos deuses ${ }^{\text {io }}$.

Apesar disso, o que se segue na narrativa são inúmeras e quase ininterruptas guerras; e o elogio a Numa e à religiosidade romana não obscurece o julgamento dos povos vizinho sobre a natureza violenta da nova cidade: "um campo de batalha situado entre eles".

Mais tarde, este grupo armado, assentado e relativamente pacificado, é ordenado de tal modo que cada homem terá a correspondência de seu lugar na ciuitas ao seu lugar no exército, segundo a reforma realizada por Sérvio Túlio:

Assim como Numa foi o fundador de nossas fundações religiosas, a posteridade atribui a Sérvio a divisão da ciuitas em ordens, que distingue os diversos graus de dignidade e de fortuna. Instituiu o censo, iniciativa muito salutar para a futura grandeza do império, que impunha a cada cidadão a obrigatoriedade de contribuir para os gastos do estado na paz e na guerra, não mais por uma taxa única como antes, mas de acordo com suas rendas. Dividiu a população em classes e centúrias, e baseado no censo criou essa organização admirável do ponto de vista civil e militar ${ }^{\mathrm{II}}$.

No livro I, cap. 43, é feita a divisão propriamente dita das centúrias. Mesmo com a passagem da monarquia para a república teria se mantido, em linhas gerais, essa divisão que vincula em cada cidadão o status na paz e na guerra.

Em resumo, de acordo com a narrativa de Tito Lívio, os feitos romanos, internos e externos, estão em permanente relação e, da origem à constituição das instituições, não poderiam ser explicados uns sem os outros.

Da narrativa de Tito Lívio ao comentário de Maquiavel, na sintética reconstrução narrativa dos Discorsi, essa relação se apresenta como fundadora da forma política romana e, potencialmente, de qualquer forma política em que se quiser "criar um povo numeroso e armado" para "criar um grande império". Deste modo, nos Discorsi, ou seja, na interpretação que Maquiavel dá para a constituição de Roma, a formação de um exército pelo povo é essencial para explicar a formação da república romana, sua fortuna militar e

\footnotetext{
${ }^{\mathrm{IO}}$ TITO LÍVIO, História de Roma, I,2I.

${ }^{\text {II }}$ TITO LÍVIO, História de Roma, I,42.
} 
sua liberdade interna e externa; segundo ele, as duas coisas, armas e forma política, são indissociáveis, como muitas vezes foi discutido nos comentários da sua obra.

Isso nos traz ao questionamento inicialmente levantado acerca da ausência do tema das armas no início da História de Florença, uma vez que não é a paz que a justifica, mas uma escolha do narrador que julga que essas questões foram suficientemente tratadas por outros historiadores, desobrigando-o por um lado de retornar a elas, por outro abrindo a possibilidade de concentrar-se nas coisas internas, até então negligenciadas. Trata-se, pois, de compreender, a razão pela qual, diante do modelo historiográfico seguido e dessa compreensão da política exposta nos Discorsi, uma narrativa histórica da origem de uma cidade poderia se constituir sem essa forma narrativa na qual as coisas internas e as externas são indissociáveis?

O primeiro aspecto da resposta reside na diferença entre a origem de Roma e a de Florença. Ao contrário de Roma, que tem uma origem livre, a de Florença é servil:

No início dos Discorsi, falando das colônias, Maquiavel afirma:

E, como tais cidades não são livres na origem, raras são as vezes em que realizam grandes progressos [processi], e entre elas é possível contar as que são capitais de reinos. Semelhante a essa foi a edificação de Florença, sob o império romano (que ou foi edificada pelos soldados de Sila, ou pelos habitantes dos montes de Fiesole, que, confiantes na paz que houve no mundo no tempo de Otaviano, reuniram-se para morar na planície, às margens do Arno): e assim não seria possível, em seus primórdios, aumentar seus territórios além daqueles que por cortesia do príncipe lhes eram concedidos ${ }^{\mathrm{I} 2}$.

Ainda que a liberdade interna não coincida com a externa e que seja possível ter uma sem a outra, a liberdade externa parece preceder em grande medida as possibilidades internas. A própria grandeza da cidade, em termos quantitativos, condiciona sua potência e nenhuma liberdade sobrevive sem a expansão das forças. A liberdade propriamente dita, isto é, em toda sua extensão, é própria dos que governam os outros, não dos que são governados.

A origem servil, entretanto, não implicará uma história pacífica, nem a ausência do impulso de conquista.

${ }^{\mathrm{I} 2}$ MAQUIAVEL, Discorsi, I, I. 
O segundo livro, da origem de Florença até I353, é basicamente composto pelos assuntos internos de Florença, pela narrativa das divisões internas. De início, estas divisões ocorrem no interior da nobreza (entre os partidos guelfos e gibelinos e os neri e bianchi), depois entre o povo e os nobres, até o momento em que o povo vence os nobres e assume o poder. O terceiro livro (1353 a I4I4) continua a tratar das divisões internas, a princípio entre os guelfos e o partido anti-guelfo, e depois entre o povo e a plebe, até o momento em que a plebe é vencida e o poder retorna ao partido guelfo. No quarto livro (I4I4 a I434), a disputa pelo poder volta a dividir os guelfos e seus adversários, que nesta época já são dirigidos por Cosimo de' Medici, que conta com o apoio da plebe.

Já no Proêmio, quando é feito o elogio à grandeza de Florença, podemos perceber o problema relativo às armas florentinas que se desenvolve no percurso do livro I ao 4:

Porque se sabe que, depois de expulsarem os gibelinos em número tão grande que enchia a Toscana e a Lombardia, os guelfos extraíram da cidade, daqueles que ficaram, dos seus cidadãos, mil e duzentos cavaleiros e doze mil infantes, para a guerra contra Arezzo, um ano antes da batalha de Campaldino[1289]; depois, na guerra que travaram contra Filippo Visconti, duque de Milão [início do século XV], quando precisaram valerse de sua indústria, e não das armas próprias, que naqueles tempos eram nulas, viu-se que, nos cinco anos em que perdurou aquela guerra, os florentinos gastaram três milhões e quinhentos mil florins; e, terminada a guerra, não contentes com a paz, para mostrarem mais o poder de sua cidade, sitiaram Lucca ${ }^{\text {I3 }}$.

A grandeza, que se expressava em número de homens em Roma e no início da república florentina, passa a se expressar em dinheiro, que já é o sinal da decadência da força pela incapacidade de unir a indústria às armas.

Lembramos então dos Discorsi, em que é demonstrado com grande número de exemplos antigos e modernos que o nervo da guerra não é o ouro:

Digo, portanto, que o nervo da guerra não é o ouro, como afirma a opinião comum, mas sim os bons soldados: porque o ouro não é suficiente para

\footnotetext{
${ }^{13}$ MAQUIAVEL, História de Florença, Proêmio.
} 
encontrar bons soldados, mas os bons soldados são bem suficientes para encontrar ouro. Se os romanos tivessem desejado travar guerras mais com dinheiro que com ferro, não lhes teria sido suficiente todo o tesouro do mundo, em vista dos grandes feitos que realizaram e das dificuldades que neles havia ${ }^{\mathrm{I}}$.

No início do livro 2 da História de Florença, Maquiavel ensaia a aproximação com a história romana, tal como apresentada em seus Discorsi, tanto na forma como no conteúdo. Ele narra que, depois da divisão e da luta entre guelfos e gibelinos, iniciada em I215, que, em razão do apoio de Frederico II resulta no exílio dos guelfos, a cidade de Florença é reunida com o retorno dos guelfos exilados, em I250: "unidos, acharam que já era tempo de tomarem uma forma livre e uma ordenação para poderem defender-se, antes que o novo imperador ganhasse força"15.

Em seguida, é relatada a instituição de ordenações civis e militares. E no capítulo seguinte, percebemos que os bons fundamentos (ordenações militares e civis) são dados, nesse momento, novamente depois de mais uma ordenação:

Com essas ordenações militares e civis os florentinos fundavam sua liberdade. E não se consegue imaginar quanta autoridade e força Florença conquistou em pouco tempo; e tornou-se não só a cidade mais importante da Toscana, como também era contada entre as primeiras cidades da Itália; e teria alcançado qualquer grandeza, se frequentes e novas divisões não a tivessem afligido. Os florentinos viveram sob esse governo dez anos...16

Depois disso, são narradas as novas lutas internas, a derrota e o exílio dos guelfos, o acordo dos guelfos com o papa e o estabelecimento das Artes. Segue-se o retorno dos guelfos exilados, as disputas e o exílio dos gibelinos. Finalmente, é feita a reordenação do estado da cidade: "Os florentinos, então, conseguiram manter sua reputação por virtù desse novo governo: dentro, com as leis; fora, com as armas"17. Essa reordenação é, entretanto, frágil. Com o retorno dos gibelinos, retomam-se as disputas entre o povo e os poderosos (podemos perceber na escrita a construção em paralelo com a derrubada dos Tarquínios ${ }^{\mathrm{I}}$ ):

\footnotetext{
${ }^{14}$ MAQUIAVEL, Discorsi, I, Io.

${ }^{15}$ MAQUIAVEL, História de Florença, II,4.

${ }^{16}$ MAQUIAVEL, História de Florença, II, 5.

${ }^{17}$ MAQUIAVEL, História de Florença, II,IO.

${ }^{\mathrm{I} 8}$ Cf. MAQUIAVEL, Discorsi, I, 3.
} 
As guerras externas e a paz interna haviam como que extinguido em Florença os partidos gibelinos e guelfos; ficaram acesos apenas os humores que naturalmente costumam existir em todas as cidades entre os poderosos e o povo; porque, visto que o povo quer viver de acordo com as leis, e os poderosos querem comandá-las, não é possível que se ajustem. Esse humor, que ficou encoberto enquanto os gibelinos infundiam medo, mostrou-se com toda a sua força tão logo estes foram dominados; e todos os dias algum popular era ultrajado, não bastando as leis e os magistrados para vingá-lo, porque qualquer nobre se defendia com parentes e amigos das forças dos priores e do capitão [do povo $]^{19}$.

Em consequência dessas violências dos poderosos, temos a reação do povo; a narrativa então passa às ações de Giano dela Bella (1293) e à instauração dos Ordenamentos de justiça, que dão reputação ao povo, isto é, aos comerciantes. Este é um momento considerado por autores como Leonardo Bruni como instaurador da liberdade florentina, mas não para Maquiavel, para quem esse é mais um momento em que, ao invés de se aprender e criar mecanismos para lidar com o conflito, se escolhe a eliminação do outro. A construção e consolidação da liberdade comunal ocorrem com a instauração dos Ordenamentos de Justiça, em 1293, que são considerados a Magna carta da nova constituição da comuna florentina e a base teórica de sua constituição até o XV. Esse processo retira autoridade da nobreza guerreira para concentrá-la nas mãos da burguesia mercantil, pois os Ordenamentos de Justiça foram criados para conter a violência às pessoas e aos bens praticadas pelos nobres, contra os populares e impotentes, tanto no campo como na cidade. ${ }^{20}$ Em sua análise do fortalecimento da classe mercantil, Maquiavel indicava a possibilidade de Florença tornar-se forte pelas armas e pelo comércio, daí a necessidade de não excluir nenhuma parte da cidade; a ênfase não é na concórdia, mas na possibilidade de encontrar um acordo mínimo para coexistirem e, sem isso, as possibilidades repetidamente se abrem e fecham.

O capítulo seguinte trata da união dos nobres, da disputa dos nobres com o povo, e do acordo com o abrandamento das leis que penalizavam os nobres. As armas são

\footnotetext{
${ }^{19}$ MAQUIAVEL, História de Florença, II, I2.

${ }^{20} \mathrm{Em}$ sua análise do fortalecimento da classe mercantil, Maquiavel indicava a possibilidade de Florença tornar-se forte com as armas e com o comércio, daí a necessidade de não excluir nenhuma parte da cidade; a ênfase não é na concórdia, mas na possibilidade de encontrar um acordo mínimo para coexistirem e, sem isso, as possibilidades repetidamente se abrem e fecham.
} 
depostas, mas a animosidade persiste, o que não é um problema para Maquiavel, pois o conflito não pode levar à eliminação do outro:

\begin{abstract}
Nunca o estado de nossa cidade foi melhor e mais feliz do que naqueles tempos, visto que seus homens estavam cheios de riquezas e reputação: os cidadãos aptos às armas chegavam a trinta mil na cidade e a setenta mil na zona rural; todas as cidades da Toscana lhe obedeciam, em parte como súditas, em parte como aliadas; e, embora entre os nobres e o povo houvesse alguma indignação e suspeita, tais coisas não produziam nenhum efeito maligno, e todos viviam unidos e em paz. E, se tal paz não fosse perturbada por novas inimizades internas, as de fora não eram de recear; porque a cidade tinha condições para já não temer o Império nem os seus exilados, e com suas forças podia responder a todos os estados da Itália. No entanto, o mal que as forças externas não lhe podiam fazer foilhe feito pelas internas.
\end{abstract}

Segue-se a disputa entre duas famílias nobres, os Cerchi e os Donati, aprofundada pela oposição entre Neri e Bianchi.Nesse meio tempo há a guerra contra Lucca e a Tirania do Duque de Atenas. Depois disso, renovam-se as lutas entre os Grandes e o Povo e os nobres são vencidos pelas armas.

Vencidos os Grandes, o povo reordenou o estado; e, como havia três espécies de povo, o poderoso, o mediano e o baixo [potente, mediocre, basso], estabeleceu-se que os poderosos teriam dois Senhores, os medianos, três, e o baixo, três; o gonfaloneiro deveria ser ora de uma, ora de outra espécie. Além disso, foram restabelecidas todas as ordenações da justiça contra os Grandes; e, para torná-los mais fracos, misturaram muitos deles à multidão popular. A ruína dos nobres foi tão grande e afligiu de tal modo seu partido que nunca mais ousaram empunhar armas contra o povo; aliás, foram-se tornando cada vez mais humanos e abjetos. Essa foi a razão de Florença ter ficado desprovida não só de armas, mas também de generosidade ${ }^{21}$.

O comentário sobre os males causados pela ruína dos nobres continua no proêmio do livro seguinte:

\footnotetext{
${ }^{21}$ MAQUIAVEL, História de Florença, II, 42.
} 
Por isso, com as vitórias do povo, a cidade de Roma se tornava mais virtuosa, porque o povo, podendo ocupar a administração das magistraturas, dos exércitos e dos impérios com os nobres, enchia-se da mesma virtù que havia nesses, e a cidade, ganhando virtù, ganhava poder; mas em Florença, quando o povo vencia, os nobres ficavam privados das magistraturas e, para reconquistá-las, precisavam não só ser mas também parecer semelhantes ao povo no comportamento, no modo de pensar e de viver. Daí provinham as variações das insígnias e as mudanças dos títulos das famílias, que os nobres faziam para parecer-se com o povo; de tal modo que a virtù das armas e a generosidade de ânimo que havia na nobreza se extinguia, sem que pudesse reacender-se no povo, no qual não existia; assim, Florença foi-se tornando cada vez mais humilde e abjeta ${ }^{22}$.

Na leitura de Maquiavel, a construção da liberdade florentina trouxe consigo as razões de sua finitude; a exclusão dos nobres guerreiros e os instrumentos do facciosismo foram necessários para o estabelecimento da autoridade popular, mas criaram as condições da senhoria dos Medici.

Há, de fato, na História de Florença, assim como na História de Roma, a narrativa da forma militar construída em relação ao modo interno de lidar com o conflito. Contudo, trata-se de uma narrativa negativa, não da constituição, mas das impossibilidades e da destruição do que havia. Enquanto, em Roma, a guerra e as inclinações guerreiras do povo constroem as relações de autoridade na cidade, em Florença, as relações de autoridade destroem as possibilidades bélicas. Depois do percurso dos quatro livros, ao introduzir o quinto, Maquiavel lamenta a decadência das armas e, consequentemente, da grandeza florentina e italiana:

Portanto, se da virtù desses novos principados não surgiram tempos que fossem tranquilos pela longa paz, também não surgiram tempos que a aspereza da guerra tornasse perigosos; porque não se pode afirmar que existe paz onde os principados vivem em constantes ataques mútuos, ao passo que não se pode dizer que há guerra quando os homens não se matam, quando as cidades não são saqueadas e os principados não são destruídos: pois tais guerras foram tão fracas que começavam sem medo, eram travadas sem perigo e terminavam sem danos (...) E se, ao 
descrevermos as coisas ocorridas nesse mundo degenerado, não falarmos da forteza dos soldados, da virtù dos comandantes, ou do amor dos cidadãos à pátria, veremos com que fraudes, astúcias e artes se comportaram os príncipes, os soldados e os governantes das repúblicas, para manterem a reputação que não mereciam. O que talvez não seja menos útil conhecer do que as coisas antigas, porque, se aquelas incitam os ânimos liberais a segui-las, estas as incitam a evitá-las e eliminá-las ${ }^{23}$.

Ao fazer o balanço da situação florentina nessa primeira fase de formação, mais que o primeiro capítulo do livro 2, que se demora na discussão do nome da cidade, é o último capítulo do livro I, em que Maquiavel sintetiza as razões pelas quais a Itália se tornou serva dos bárbaros, que funciona como prefácio do livro 2. Neste capítulo, ele discute a situação das armas italianas no início do século XV:

Os florentinos obedeciam às mesmas necessidades, porque, visto que sua nobreza fora extinta em suas frequentes divisões, aquela república estava nas mãos de homens formados no comércio, que seguiam as ordenações e a fortuna dos outros. As armas da Itália, portanto, estavam nas mãos de príncipes menores ou de homens sem estado; porque os príncipes menores os assumiam não movidos pela glória, mas sim pelo desejo de viverem mais ricos ou mais seguros, ao passo que os outros, por terem sido formados nas armas desde pequenos, não sabendo praticar outra arte, procuravam por meio delas honrar-se como ricos ou poderosos ${ }^{24}$.

Falando dos mercenários, as únicas armas italianas efetivamente atuantes em seu tempo, diz que:

estes, por estarem sempre em pé de guerra, haviam formado uma espécie de liga e de inteligência comum, transformando-a em arte; e tanto temporizavam que, no mais das vezes, ambas as partes em guerra saíam perdedoras; até que, por fim, reduziram a arte das armas a uma situação tão vil que qualquer capitão medíocre, com uma sombra da antiga virtù, os cobriria de vergonha, para grande admiração de toda a Itália, que, por

\footnotetext{
${ }^{23}$ MAQUIAVEL, História de Florença, IV,I.

${ }^{24}$ MAQUIAVEL, História de Florença, I, 39.
} 
pouca prudência, os honrava. Portanto, minha história estará cheia de tais príncipes ociosos e de tais exércitos vis ${ }^{25}$.

Diante desta análise das origens e perspectivas italianas, propomos a leitura do capítulo 26 do Príncipe, que pode ocupar, no Príncipe, o lugar histórico do início, isto é, da fundação. A despeito de toda disputa acerca de seus objetivos e deixando de lado o tom elevado que nos inspira suspeita e o destinatário improvável, nele encontramos a busca pela liberdade externa que precede a da liberdade interna: o chamado para uma nova fundação, marcada pela origem livre.

Ainda que até agora se tenha mostrado algum vislumbre em alguém, a ponto de se julgar ter sido ele ordenado por Deus para sua redenção, o que se viu depois, no entanto, no auge de sua carreira, foi ser ele reprovado pela fortuna. Desse modo, permanece a Itália como que sem vida, à espera de quem sane suas feridas e ponha fim ao saque da Lombardia, à espoliação do Reino [de Nápoles] e da Toscana e a cure de suas chagas há muito tempo ulceradas. Vê-se que a Itália roga a Deus para que lhe envie alguém para redimi-la da crueldade e da insolência dos bárbaros; vê-se que está inteiramente pronta e disposta a seguir uma bandeira, contanto que alguém a tome ${ }^{26}$.

E, mais à frente, num tom mais moderado, Maquiavel aponta para seus bons fundamentos:

Não é de maravilhar que alguns dos italianos antes mencionados não tenham podido fazer o que se espera seja feito por vossa ilustre Casa, tampouco que, depois de tantas revoluções e manobras de guerra na Itália, pareça para sempre ter-se extinguido sua virtù militar. Isso decorre de não terem sido boas suas antigas ordenações, como também de não ter aparecido ninguém que soubesse encontrar novas. Coisa alguma honrará tanto um homem que acaba de elevar-se quanto as novas leis e as novas ordenações encontradas por ele. Quando bem fundamentadas e quando trazem em si grandeza, essas coisas fazem-no reverenciado e admirado. $\mathrm{Na}$ Itália, não falta matéria para introduzir todas as formas ${ }^{27}$.

\footnotetext{
${ }^{25}$ MAQUIAVEL, História de Florença, I, 39.

${ }^{26}$ MAQUIAVEL, O Príncipe, XXVI.

${ }^{27}$ MAQUIAVEL, O Príncipe, XXVI.
} 


\section{Referências Bibliográficas}

BRUNI, Leonardo. Istoria fiorentina di Leonardo Aretino, [tradotta in volgare da Donato Acciajuoli; premessovi un Discorso su Leonardo Bruni aretino per C. Monzani]. Firenze, F. Le Monnier, I86I.

CABRINI, Anna Maria. Un'idea di Firenze. Da Villani a Guicciardini. Roma, Bulzoni Editore, $200 I$.

COCHRANE, Eric. Historians and Historiography in the Italian Renaissance. Chicago, University of Chicago Press, I98I.

GILBERT, Felix. Machiavelli and Guicciardini, Politics and History in Sixteenth-Century Florence. Princeton, Princeton University Press, 1965.

MACHIAVELLI. Tutte le Opere. Firenze, Sansoni, 1992.

MAQUIAVEL. Discursos sobre a primeira década de Tito Lívio. São Paulo: Martins Fontes, 2007.

MAQUIAVEL. História de Florença. São Paulo: Martins Fontes, 2007.

MAQUIAVEL. O príncipe. São Paulo: Martins Fontes, $201 \mathrm{I}$.

SALVEMINI, G. Magnati e popolani in Firenze dal I280 al I295, Einaudi, Torino I960.

TITO LÍVIO. História de Roma. São Paulo: Paumape, I989.

VILLANI, Giovanni. Nuova Cronica, Fondazione Pietro Bembo/Ugo Guanda. Biblioteca di scrittori italiani, Editore in Parma, 199I. 